\title{
Continuation rates, bleeding profile acceptability, and satisfaction of women using an oral contraceptive pill containing estradiol valerate and dienogest versus a progestogen-only pill after switching from an ethinylestradiol-containing pill in a real-life setting: results of the CONTENT study
}

\author{
This article was published in the following Dove Press journal: \\ International Journal of Women's Health \\ 15 September 2016 \\ Number of times this article has been viewed
}

Paula Briggs

Marco Serrani²

Kai Vogtländer ${ }^{3}$

Susanne Parke

'Sexual and Reproductive Health, Southport and Ormskirk Hospital NHS Trust, Merseyside, UK; ${ }^{2}$ Global Medical Affairs Women's HealthCare, Bayer Pharma AG, Berlin, ${ }^{3}$ Global Integrated Analysis \& Life Cycle Management Statistics, Bayer Pharma AG, Wuppertal, ${ }^{4}$ Global Clinical

Development Women's HealthCare, Bayer Pharma AG, Berlin, Germany
Correspondence: Paula Briggs

The May Logan Centre, 294 Knowsley

Road, Bootle L20 5 DQ, UK

Tel +447976696497

Fax +44 I5I 9446525

Email paulaeb@aol.com
Background: Oral contraceptives are still associated with high discontinuation rates, despite their efficacy. There is a wide choice of oral contraceptives available, and the aim of this study was to assess continuation rates, bleeding profile acceptability, and the satisfaction of women in the first year of using a contraceptive pill containing estradiol valerate and dienogest $\left(\mathrm{E}_{2} \mathrm{~V} / \mathrm{DNG}\right)$ versus a progestogen-only pill (POP) in a real-life setting after discontinuing an ethinylestradiol-containing pill.

Methods and results: In this prospective, noninterventional, observational study, 3,152 patients were included for the efficacy analyses $\left(n=2,558\right.$ women in the $E_{2}$ V/DNG group and $n=592$ in the POP group (two patients fulfilled the criteria of the efficacy population, but the used product was not known). Women had been taking an ethinylestradiol-containing pill $\geq 3$ months before deciding to switch to the $E_{2} V / D N G$ pill or a POP. Overall, $19.8 \%(n=506)$ of $E_{2} V / D N G$ users and $25.8 \%(n=153)$ of POP users discontinued their prescribed pill. The median time to discontinuation was 157.0 days and 127.5 days, respectively. Time to discontinuation due to bleeding $(P<0.0001)$ or other reasons $(P=0.022)$ was significantly longer in the $\mathrm{E}_{2} \mathrm{~V} / \mathrm{DNG}$ group versus the POP group. The $\mathrm{E}_{2} \mathrm{~V} / \mathrm{DNG}$ pill was also associated with shorter $(48.7 \% \mathrm{vs}$ $44.1 \%$ ), lighter ( $54 \%$ vs $46.1 \%$ ), and less painful bleeding $(91.1 \%$ vs $73.7 \%$ ) and greater user satisfaction $(80.7 \%$ vs $64.6 \%)$ than POP use, within 3-5 months after switch.

Conclusion: The $\mathrm{E}_{2} \mathrm{~V} / \mathrm{DNG}$ pill was associated with higher rates of continuation, bleeding profile acceptability, and user satisfaction than POP use and may be an alternative option for women who are dissatisfied with their current pill.

Keywords: contraception, oral contraceptive, compliance, estradiol valerate, dienogest

\section{Introduction}

Oral contraceptives (OCs) have proved to be a popular method of contraception with $>100$ million women estimated to use them worldwide, since their introduction in the $1960 \mathrm{~s} .{ }^{1}$

Despite being one of the most effective forms of contraception and there being an ever-widening choice of OCs to suit the individual needs of women, a high percentage of users discontinue OCs for various reasons, leading to an increased risk 
of unintended pregnancy, if not replaced by a comparably effective method. ${ }^{2}$

Indeed, prospective survey data have shown that fourfifths of women who stopped OCs subsequently failed to adopt another method or chose a less effective form of contraception. ${ }^{2,3}$ Other studies have found that there is a high rate of discontinuation within the first 1-2 years of OC use and that method-related reasons, notably the occurrence of side effects such as bleeding irregularities, were the most commonly cited causes. ${ }^{3,4}$

Progestogen-only pills (POPs) in particular are associated with problematic (unscheduled) bleeding, a common reason for discontinuation in up to $25 \%$ of users, that can affect adherence. ${ }^{5,6}$ Rates of discontinuation with POPs have been noted to vary according to the progestogen content, ${ }^{7,8}$ although a recent review found that there were insufficient data to compare POPs with each other or with combined OCs (COCs). ${ }^{8}$

Lower rates of discontinuation have been observed with COCs than with POPs, with an inverse relationship to the dose of ethinylestradiol (EE) used. ${ }^{4}$ The results of a Cochrane review ${ }^{9}$ found that discontinuation rates were higher for OCs containing very low doses of EE compared with higher-dose estrogen preparations.

In a European clinical trial, ${ }^{10} \mathrm{a}$ COC containing estradiol valerate and dienogest $\left(\mathrm{E}_{2} \mathrm{~V} / \mathrm{DNG}\right)$ in a dynamic dosing regimen (Qlaira ${ }^{\circledR}$ Natazia $^{\mathrm{TM}}$; Bayer AG, Leverkusen, Germany) reported that only $2.5 \%$ of women discontinued treatment prematurely due to bleeding irregularities.

Although it is now well known that most women using POPs stop their pill for method-related reasons within the first year of use, there is limited information on continuation rates due to user acceptability of bleeding profile changes and overall satisfaction with the $\mathrm{E}_{2} \mathrm{~V} / \mathrm{DNG}$ pill in a real-life setting. As bleeding patterns may influence continuation rates more typically in POP use, $\mathrm{E}_{2} \mathrm{~V} / \mathrm{DNG}$ users were compared with POP users to assess the acceptability of the bleeding profile, the continuation rates, and user satisfaction. The CONTENT study (ClinicalTrials.gov identifier: NCT01200186) was specifically designed to look at these parameters in the first year of use of the $\mathrm{E}_{2} \mathrm{~V} / \mathrm{DNG}$ pill, compared with a POP, after switching from a COC-containing EE.

\section{Methods}

\section{Study design and participants}

CONTENT was a Phase IV, prospective, multicenter, noninterventional, observational study in women (aged 18-50 years) switching from an EE-containing OC pill to the $E_{2} V / D N G$ pill or a POP. The study was conducted at 375 investigational sites in eleven countries: the Czech Republic, France, Germany, Greece, Hungary, Israel, Italy, the Russian Federation, Slovakia, Sweden, and the UK. Approval by independent ethics committees or institutional review boards was obtained in each country where required (Table S1). All patients provided written informed consent.

For inclusion, women must have been using EEcontaining OCs for $\geq 3$ months prior to enrollment and must have decided to switch either to the $\mathrm{E}_{2} \mathrm{~V} / \mathrm{DNG}$ pill or to a POP, depending on individual choice. Exclusion criteria were in accordance with the contraindications, precautions, and warnings for women receiving the $\mathrm{E}_{2} \mathrm{~V} / \mathrm{DNG}$ pill or chosen POP based on the approved product labeling in each country. Women who were breastfeeding were also excluded.

The $\mathrm{E}_{2} \mathrm{~V} / \mathrm{DNG}$ pill was administered via a dynamic dosing regimen $\left(\mathrm{E}_{2} \mathrm{~V} 3 \mathrm{mg}\right.$ on days 1 and $2, \mathrm{E}_{2} \mathrm{~V} 2 \mathrm{mg} / \mathrm{DNG}$ $2 \mathrm{mg}$ on days $3-7, \mathrm{E}_{2} \mathrm{~V} 2 \mathrm{mg} / \mathrm{DNG} 3 \mathrm{mg}$ on days $8-24, \mathrm{E}_{2} \mathrm{~V}$ $1 \mathrm{mg}$ on days $25-26$, and placebo on days 27-28). The chosen POP was administered according to the relevant prescribing information. As this is a noninterventional study, the duration of treatment was at the discretion of the physician. Women were followed for 1 year.

\section{Assessment and study outcomes}

The overall aim was to assess continuation rates and user acceptability of any bleeding changes and satisfaction with the $\mathrm{E}_{2} \mathrm{~V} / \mathrm{DNG}$ pill and selected POPs in a real-life setting.

Women taking an EE-containing pill were assessed before they decided to switch to the $\mathrm{E}_{2} \mathrm{~V} / \mathrm{DNG}$ pill or to a POP (visit 1). At this initial screening visit, the medical, surgical, and gynecological history (including age at menarche and reproductive history), previous POP experience and reasons for stopping the current pill were recorded. Bleeding patterns during the preceding 3 months were evaluated, with repeat assessment at 3-5 months (visit 2) and again at 6-12 months (visit 3).

The primary outcome assessment was the time to discontinuation due to unacceptable bleeding during the first year of use, and the main secondary outcome measure was the time to discontinuation for other reasons. Other secondary outcomes included the cumulative discontinuation rate according to bleeding regularity (ie, unscheduled, infrequent, or absent), intensity (ie, heavy and/or prolonged), and the presence of pain in association with bleeding. Other medical reasons (eg, adverse event [AE], change in medical eligibility) and nonmedical reasons (eg, study consent withdrawn, poor adherence) for discontinuation were recorded.

At visits 2 and 3, women self-assessed their satisfaction and well-being using a five-point category scale $(1=$ much 
worse to $5=$ much better, compared with baseline). AEs were carefully assessed and recorded, whether or not related to the use of either pill.

\section{Statistical analyses}

Sample size was selected based on an assumed discontinuation rate of $5 \%$ for the $\mathrm{E}_{2} \mathrm{~V} / \mathrm{DNG}$ pill and $10 \%$ for POP at 1 year. Assuming a significance level of 5\% (two-sided log-rank test) and a power of $90 \%, \sim 600$ patients had to be enrolled per treatment group for a 1:1 allocation. However, in the real-life setting of a noninterventional study, the allocation ratio cannot be stipulated. The ratio of women in each group (E 2 /DNG:POP) of 1:4 to 4:1 was dependent on utilization of each contraceptive pill across centers. For the sample size calculation, a ratio of 1:1 was assumed for the calculation of the size of the smaller treatment group. This approach led to a total sample size of 3,000 patients and allowed a power of at least $90 \%$ for all allocation ratios.

Time-to-event for discontinuation due to unacceptable bleeding or due to other reasons was calculated and analyzed by means of the Kaplan-Meier estimator. Time until discontinuation was censored at the end of observation, if no discontinuation was reported until the end of observation.

Treatment groups were compared based on a proportional hazard model, and propensity score methods (as detailed in the Supplementary materials) were applied by an outcome-blinded third party (Stat-Epi Associates, Inc., South Ponte Vedra Beach, FL, USA) to account for allocation bias and possible confounding factors.

Descriptive analysis of the data, including user satisfaction and well-being, was performed using basic summary statistics. Continuous data were described by median, mean, standard deviation, minimum, maximum, and 25 and 75 percentiles. Categorical data, including categories of continuous data, were presented in frequency tables. The number of participants with missing data was presented as a separate category.

The primary and secondary outcomes were analyzed for all women. Safety analyses were conducted for all women who took at least one dose of the study drug (defined as safety population).

\section{Results}

Of a total of 3,258 women who were enrolled, 3,152 women had data available for efficacy assessment and 3,237 formed the safety population. Of these, 2,558 (81.2\%) and 2,629 $(81.2 \%)$ in each group received the $\mathrm{E}_{2} \mathrm{~V} / \mathrm{DNG}$ pill and 592 (18.8\%) and $605(18.7 \%)$ received a POP. For two women in the efficacy population and three in the safety population, the treatment could not be defined, and therefore their data were not analyzed in detail. The majority $(>80 \%)$ of POPs used by women participating in the study contained desogestrel.

Except for participants' smoking status, there were no relevant differences between the two study groups in terms of their demographic data (Table 1).

Both study groups were also well balanced in terms of the bleeding pattern at baseline (Table S2). In the 3 months prior to discontinuing their EE-containing pill, the majority $(85 \%)$ of women experienced regular bleeds in both the $\mathrm{E}_{2} \mathrm{~V} /$ DNG and POP groups, with $\sim 13 \%$ experiencing occasional or absent bleeding and 1\%-2\% amenorrhea. The minimum duration of bleeding, maximum intensity of bleeding, and percentage of women with painful or intracyclic bleeding were also comparable at baseline.

Reasons for discontinuing the prior EE-containing pill and switching to either the $\mathrm{E}_{2} \mathrm{~V} / \mathrm{DNG}$ pill or to a POP differed between the two groups. The most common reasons given by participants who switched to the $\mathrm{E}_{2} \mathrm{~V} / \mathrm{DNG}$ pill were that they "want to try something else" (36.6\%), received a "recommendation" (34.2\%) from a health care provider, or had experienced "side effects (other than bleeding-related)" $(24.0 \%)$. In women who switched to a POP, the most common reasons given for subsequent discontinuation of the method were "side effects (other than bleeding-related)" (23.5\%), "contraindications" (22.5\%), "smoking" (21.3\%), and that they had received a "recommendation" (20.9\%) to do so.

Table I Baseline demographic characteristics

\begin{tabular}{|c|c|c|c|c|c|c|}
\hline \multirow[t]{2}{*}{ Variable } & \multicolumn{2}{|c|}{$\begin{array}{l}\text { Total } \\
(\mathrm{N}=3,150)\end{array}$} & \multicolumn{2}{|c|}{$\begin{array}{l}E_{2} \text { V/DNG } \\
(n=2,558)\end{array}$} & \multicolumn{2}{|c|}{$\begin{array}{l}\text { POP } \\
(n=592)\end{array}$} \\
\hline & $n$ & $\%$ & $\mathbf{n}$ & $\%$ & $\mathbf{n}$ & $\%$ \\
\hline \multicolumn{7}{|l|}{ Age (years) } \\
\hline $18-25$ & 706 & 22.4 & 572 & 22.4 & 134 & 22.6 \\
\hline $26-34$ & $\mathrm{I}, 034$ & 32.8 & 850 & 33.2 & 184 & 31.1 \\
\hline $35-50$ & 1,215 & 38.6 & 994 & 38.9 & 221 & 37.3 \\
\hline \multicolumn{7}{|l|}{ BMI $\left(\mathrm{mg} / \mathrm{kg}^{2}\right)$} \\
\hline$<18.5$ & 169 & 5.4 & $|4|$ & 5.5 & 28 & 4.7 \\
\hline 18.5 to $<25$ & 2,281 & 72.4 & $\mathrm{I}, 872$ & 73.2 & 409 & 69.1 \\
\hline 26 to $<30$ & 492 & 15.6 & 398 & 15.6 & 94 & 15.9 \\
\hline$>30$ & 144 & 4.5 & 102 & 4.0 & 42 & 7.1 \\
\hline \multicolumn{7}{|l|}{ Educational level } \\
\hline Primary school & 85 & 2.7 & 60 & 2.3 & 25 & 4.2 \\
\hline Higher than primary school & 3,046 & 96.7 & 2,483 & 97.1 & 563 & 95.1 \\
\hline \multicolumn{7}{|c|}{ Smoking status } \\
\hline No & 2,543 & 80.7 & 2,129 & 83.2 & 414 & 69.6 \\
\hline Yes & 607 & 19.3 & 429 & 16.8 & 178 & 30.1 \\
\hline
\end{tabular}

Abbreviations: $\mathrm{BMI}$, body mass index; $\mathrm{E}_{2} \mathrm{~V} / \mathrm{DNG}$, estradiol valerate and dienogest; POP, progestogen-only pill. 


\section{Continuation of contraception}

A total of 659 (20.9\%) women discontinued their prescribed pill during the course of the study or at the end of study visit; $19.8 \%$ of women $(n=506)$ in the $\mathrm{E}_{2} \mathrm{~V} / \mathrm{DNG}$ group versus $25.8 \%$ of women $(n=153)$ in the POP group (Figure 1). The median time until discontinuation (due to any reason) was 157.0 days in the $\mathrm{E}_{2} \mathrm{~V} / \mathrm{DNG}$ group and 127.5 days in the POP group.

Kaplan-Meier and Cox regression analysis showed that the time to discontinuation was significantly longer in the $\mathrm{E}_{2} \mathrm{~V} / \mathrm{DNG}$ group than in the POP group due to bleeding $(P<0.0001)$ or other reasons $(P=0.022)$.

Propensity score-adjusted analysis to account for confounding by stratified Cox regression showed significant differences between the groups ( $P=0.0004$ and $P=0.0244$, respectively), indicating a significant treatment effect on the primary outcome.

\section{Reasons for discontinuation}

The most frequent reasons for discontinuation of the $\mathrm{E}_{2} \mathrm{~V} /$ DNG pill during the first year of use after switching from an EE-containing COC were nonmedical (44.3\%) followed by unacceptable bleeding pattern $(27.7 \%)$. Conversely, in the women switching to a POP, unacceptable bleeding patterns $(37.9 \%)$ followed by nonmedical $(31.4 \%)$ and then medical reasons (30.1\%) were the most common reasons for discontinuation. In approximately half of the patients who indicated nonmedical reasons, the wish to conceive was the most frequently given reason in both the $\mathrm{E}_{2} \mathrm{~V} / \mathrm{DNG}$ and $\mathrm{POP}$ groups ( $47.8 \%$ vs $58.3 \%$, respectively) followed by accessibility/cost (32.6\% vs $18.8 \%)$.

Women who indicated medical reasons for discontinuation stated AEs most frequently in both the $\mathrm{E}_{2} \mathrm{~V} / \mathrm{DNG}$ and POP groups ( $84.3 \%$ and $87.0 \%$, respectively). When unacceptable bleeding pattern was the reason, intracyclic bleeding

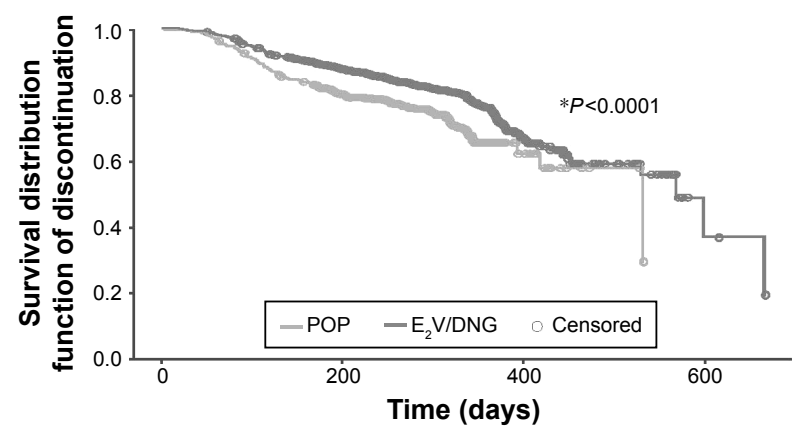

Figure I Kaplan-Meier plot of duration until discontinuation due to unacceptable bleeding or other reasons (propensity score-adjusted population analysis). Note: *Time to discontinuation for $\mathrm{E}_{2} \mathrm{~V} / \mathrm{DNG}$ vs POP.

Abbreviations: $E_{2} V / D N G$, estradiol valerate and dienogest; $P O P$, progestogenonly pill. (ie, more than once per month bleeding) was most frequently recorded in both groups ( $75.7 \%$ and $77.6 \%$, respectively).

\section{Effect on the bleeding profile}

\section{Regularity of bleeding}

The $\mathrm{E}_{2} \mathrm{~V} / \mathrm{DNG}$ pill was superior at maintaining a regular bleeding pattern (Figure 2A) in women switching from an EE-containing pill to either $\mathrm{E}_{2} \mathrm{~V} / \mathrm{DNG}$ or to a POP. The proportion of women in the $\mathrm{E}_{2} \mathrm{~V} / \mathrm{DNG}$ and $\mathrm{POP}$ groups with occasionally absent withdrawal bleeding was $13.7 \%$ in the $\mathrm{E}_{2} \mathrm{~V} / \mathrm{DNG}$ group and $12.7 \%$ in the POP group at baseline, increasing to $24.3 \%$ and $31.1 \%$ at the last visit in each group, respectively. Corresponding values for amenorrhea were $1.0 \%$ and $2.2 \%$ at baseline and $8.2 \%$ and $43.5 \%$ at the last visit.

Bleeding regularity was influenced by age, with women aged $35-50$ years having less regular bleeding than women aged $18-34$ years.

\section{Duration of bleeding}

The maximum length of bleeding decreased considerably during the study, as indicated by the increasing proportion of women with maximum length of bleeding for only 1-2 days ( $\mathrm{E}_{2} \mathrm{~V} / \mathrm{DNG}$ group: $9.5 \%$ at baseline to $48.7 \%$ at last visit; POP group: $10.9 \%$ at baseline to $44.1 \%$ at last visit). The proportions of women bleeding for 3-5 days, 6-7 days, and $\geq 8$ days at baseline and last visit in the $\mathrm{E}_{2} \mathrm{~V} / \mathrm{DNG}$ and POP groups were $65.4 \% / 45.5 \%, 20.7 \% / 3.1 \%$, and $4.2 \% / 2.5 \%$ and $69.6 \% / 34.9 \%, 15.9 \% / 10.5 \%$, and $3.3 \% / 10.5 \%$, respectively. Changes from baseline to last visit in length of bleeding are shown in Figure 2B.

\section{Intensity of bleeding}

The maximum intensity of bleeding decreased considerably from baseline with both pills, with an increasing proportion of women describing their periods as "light/scanty" at the last visit ( $\mathrm{E}_{2} \mathrm{~V} / \mathrm{DNG}$ group: $21.4 \%$ at baseline to $54.0 \%$ at last visit; POP group: $24.2 \%$ at baseline to $46.1 \%$ at last visit). The proportion of women with "normal" intensity bleeding decreased from $55.3 \%$ at baseline to $18.3 \%$ at last visit in the $\mathrm{E}_{2} \mathrm{~V} / \mathrm{DNG}$ group and from $52.9 \%$ to $15.1 \%$ in the POP group. The proportion of women with heavy bleeding was also reduced from $16.3 \%$ to $1.6 \%$ in the $\mathrm{E}_{2} \mathrm{~V} / \mathrm{DNG}$ group and from $15.4 \%$ to $4.3 \%$ in the POP group (Figure 2C).

\section{Dysmenorrhea}

The proportion of women with painless bleeding increased from $71.3 \%$ to $91.1 \%$ in the $\mathrm{E}_{2} \mathrm{~V} / \mathrm{DNG}$ group versus no 
A

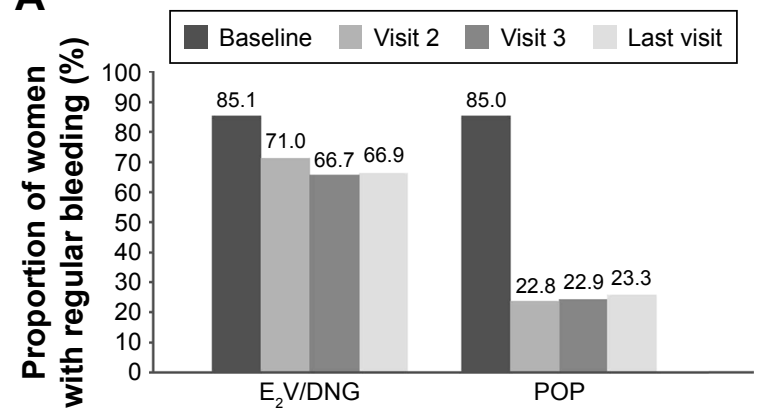

C

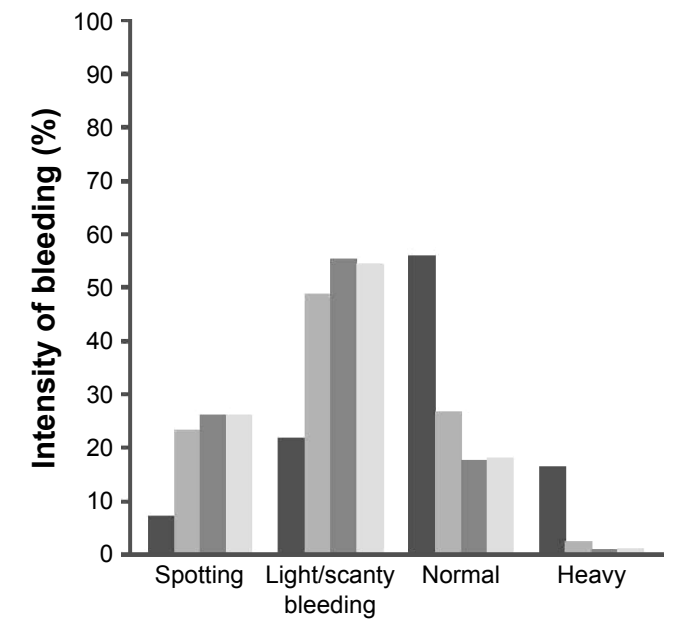

B
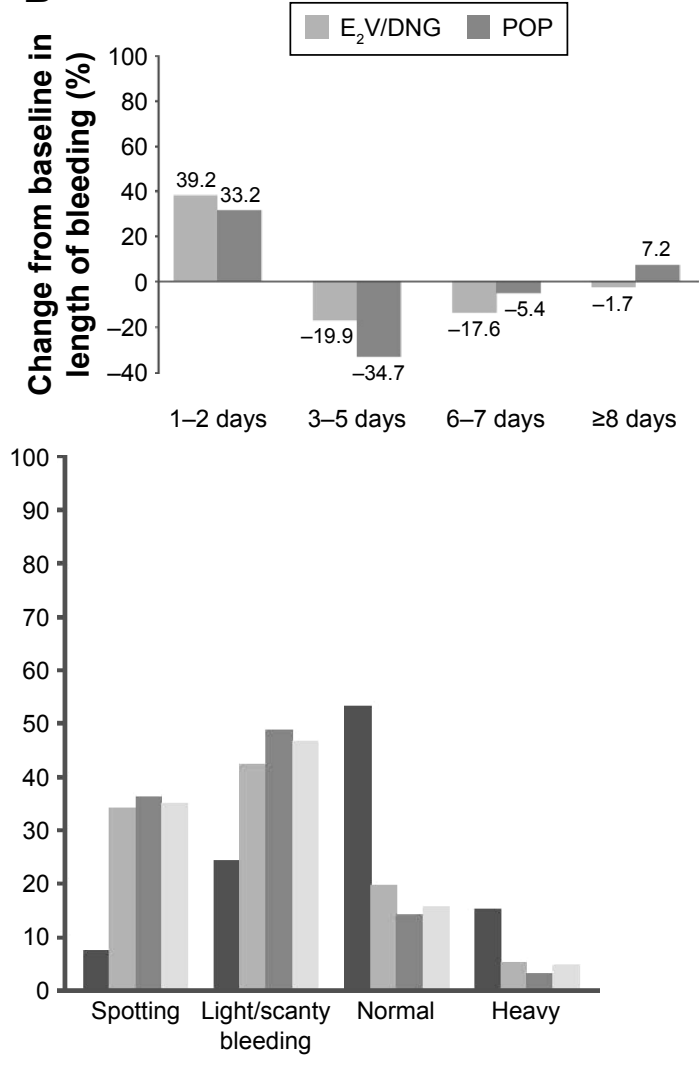

POP group

$E_{2}$ V/DNG group

Baseline Visit 2 Visit 3 Last visit

D

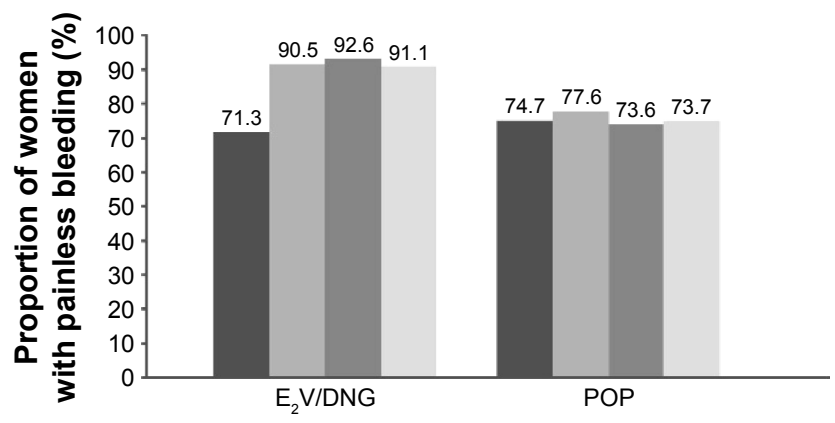

Baseline Visit 2 Visit $3 \quad$ Last visit

Figure 2 Bleeding profile changes at baseline and the last visit after switching to the $E_{2} V / D N G$ pill or POP.

Notes: Proportion of women with (A) regular bleeding (once a month); (B) change from baseline in length of bleeding; (C) light/scanty bleeding; and (D) painless bleeding. Abbreviations: $E_{2}$ V/DNG, estradiol valerate and dienogest; POP, progestogen-only pill.

change in the POP group $(74.7 \%$ at baseline and $73.7 \%$ at the last visit; Figure 2D).

\section{Problematic (unscheduled) bleeding}

The proportion of women experiencing problematic bleeding did not change considerably from baseline to last visit in the $\mathrm{E}_{2} \mathrm{~V} / \mathrm{DNG}$ group, although a slight decrease was noted compared with an increase seen in the POP group.

\section{User satisfaction with their pill}

Switching to an $\mathrm{E}_{2} \mathrm{~V} / \mathrm{DNG}$ pill was associated with a higher degree of user satisfaction than switching to a POP after only 3-5 months (visit 2), irrespective of age (Figure 3). In addition, the proportion of patients who felt "indifferent" was higher in the POP group than in the $\mathrm{E}_{2} \mathrm{~V} / \mathrm{DNG}$ group, and the proportion of women discontinuing their pill due to dissatisfaction was also higher in the POP group throughout the study. 


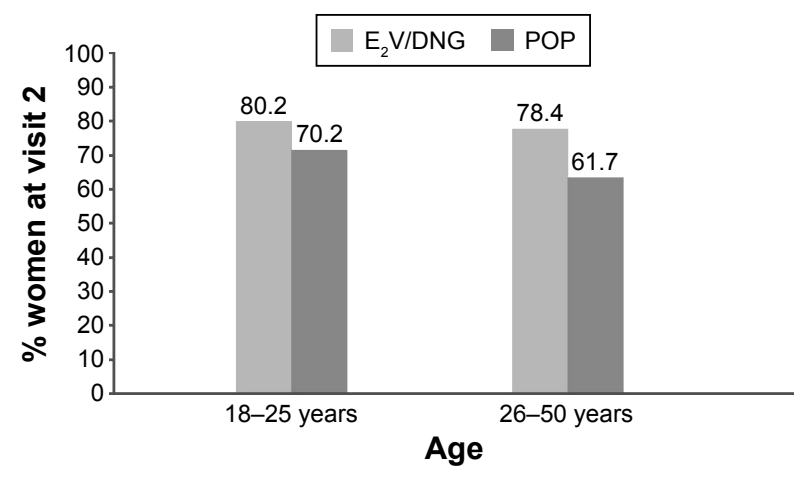

Figure 3 Percentage of women who rated their overall satisfaction as "satisfied" or "very satisfied" $3-5$ months after switching to the $E_{2} V / D N G$ pill or POP. Abbreviations: $E_{2} V / D N G$, estradiol valerate and dienogest; $P O P$, progestogenonly pill.

\section{Physical and emotional well-being}

User-reported physical well-being was reported as "better" or "much better" by $75.7 \%$ of women taking the $\mathrm{E}_{2} \mathrm{~V} / \mathrm{DNG}$ pill versus $63.0 \%$ of those taking a POP by the time of the last visit. A higher proportion of women in the $\mathrm{E}_{2} \mathrm{~V} / \mathrm{DNG}$ group also reported feeling emotionally "better" or "much better" ( $71.8 \%$ vs $56.7 \%)$ by their last visit than those in the POP group (Figure S1).

\section{Contraceptive efficacy}

Both treatments were highly effective with only two pregnancies in users of the $\mathrm{E}_{2} \mathrm{~V} / \mathrm{DNG}$ pill and one in the POP group recorded during the study period.

\section{Safety and tolerability}

Both the $\mathrm{E}_{2} \mathrm{~V} / \mathrm{DNG}$ pill and POP were generally well tolerated. The overall rates of all treatment-emergent AEs (TEAEs) were $7.4 \%(\mathrm{n}=194)$ and $11.2 \%(\mathrm{n}=68)$, respectively. Incidences of drug-related and serious TEAEs were $5.0 \%$, and $9.3 \%, 0.1 \%$, and 0.0 , for $\mathrm{E}_{2} \mathrm{~V} / \mathrm{DNG}$ and POP, respectively; drug-related TEAEs resulting in permanent discontinuation of the study pill were $5.0 \%$ and $7.8 \%$ (Table S3). The most frequently documented, drug-related TEAEs in the $\mathrm{E}_{2} \mathrm{~V} / \mathrm{DNG}$ group were headache $(1.14 \%)$, acne $(0.65 \%)$, weight increase $(0.53 \%)$, and breast pain $(0.49 \%)$. In the POP group, the most frequent drug-related TEAEs were acne (2.64\%), metrorrhagia $(1.16 \%)$, weight increase $(0.99 \%)$, and breast pain $(0.99 \%)$.

\section{Discussion}

CONTENT is a large-scale study undertaken to evaluate women's experience of using the $\mathrm{E}_{2} \mathrm{~V} / \mathrm{DNG}$ pill versus a $\mathrm{POP}$ in a real-life setting. Specifically, the study was designed to compare continuation rates, bleeding profile acceptability, and user satisfaction during the first year of use of either pill after switching from an EE-containing pill.
Results showed that switching to the $\mathrm{E}_{2} \mathrm{~V} / \mathrm{DNG}$ pill led to a higher continuation rate and significantly longer continuation time than switching to a POP. Furthermore, user satisfaction and well-being were also rated higher in women switching to the $\mathrm{E}_{2} \mathrm{~V} / \mathrm{DNG}$ pill compared with a POP.

Reasons for the better continuation and satisfaction with the $\mathrm{E}_{2} \mathrm{~V} / \mathrm{DNG}$ pill versus the $\mathrm{POP}$ may be attributed to the different bleeding profiles seen with each pill. Both pills reduced the length and intensity of bleeding and increased the rate of absent withdrawal bleeding. The incidence of painful bleeding was reduced in patients after switching to $\mathrm{E}_{2} \mathrm{~V} / \mathrm{DNG}$, whereas there was no change from baseline in the POP group. It should be noted that $\sim 70 \%$ of all patients had no painful bleeding at baseline. Given that all patients had switched from a COC, painless bleeding could be a class effect with all COCs, with a more pronounced effect seen with $\mathrm{E}_{2} \mathrm{~V} / \mathrm{DNG}$.

Although the majority of women did not experience problematic bleeding, a slight decrease from baseline (5.1\%) was seen in women taking the $\mathrm{E}_{2} \mathrm{~V} / \mathrm{DNG}$ pill compared with a slight increase of $5.9 \%$ in the POP group. Problematic (unscheduled) bleeding was originally intended to be assessed only in women who reported withdrawal bleeding. However, this was not clear from the case report form and therefore women in the POP group experiencing no withdrawal bleeding would not have been able to answer the question and their data would have been marked as "missing" and could account for the differences observed.

The $\mathrm{E}_{2} \mathrm{~V} / \mathrm{DNG}$ pill combines estradiol with dienogest in a multiphasic regimen with a shortened hormone-free interval ${ }^{11}$ and leads to stable estradiol levels throughout the whole cycle. ${ }^{12}$ This may account for the better overall outcomes seen in this study with the $\mathrm{E}_{2} \mathrm{~V} / \mathrm{DNG}$ pill when compared with POP use.

In studies examining the effects of $\mathrm{E}_{2} \mathrm{~V} / \mathrm{DNG}$ versus either EE/norgestimate ${ }^{13}$ or EE/levonorgestre ${ }^{14}$ on hormone withdrawal-associated symptoms, the shortened hormone-free interval and stable estradiol levels associated with the $\mathrm{E}_{2} \mathrm{~V} / \mathrm{DNG}$ pill led to a decrease in hormone withdrawal-associated symptoms, such as headache and pelvic pain. Further findings from a study looking at the effects of $\mathrm{E}_{2} \mathrm{~V} / \mathrm{DNG}$ versus $\mathrm{EE} /$ levonorgestre ${ }^{15}$ on dysmenorrheic pain demonstrated a significant reduction in dysmenorrhea. The benefits of the $\mathrm{E}_{2} \mathrm{~V} / \mathrm{DNG}$ pill on the bleeding pattern have also been observed in women suffering from heavy menstrual bleeding, ${ }^{16}$ and the $\mathrm{E}_{2} \mathrm{~V} / \mathrm{DNG}$ pill is the only COC indicated for treatment of this condition/indication. Heavy menstrual bleeding was noted in a proportion of patients entering this study. The $\mathrm{E}_{2} \mathrm{~V} / \mathrm{DNG}$ pill has also been shown to improve symptoms 
of COC-associated female sexual dysfunction, which is often impaired with the intake of other COCs. ${ }^{17}$

As this was a real-life setting, the study population of CONTENT was more heterogeneous than that seen in a randomized, controlled trial. For this reason, propensity score adjustment was used to help reduce the effect of allocation bias or confounding variables on the estimation of treatment effect. It is acknowledged that such methods cannot guarantee that all effects of confounders are eliminated and the effects of unmeasured confounders cannot be discounted, which may be considered a limitation of the present study. The fact that the study did not include a placebo arm or an active comparator arm means that the degree to which the results reflect drug-specific effects remains uncertain. Nevertheless, a number of randomized, controlled trials have been published, which have answered such research questions sufficiently, and the results of the CONTENT study are in accordance with the findings of the previous randomized studies involving the $\mathrm{E}_{2} \mathrm{~V} / \mathrm{DNG}$ pill $^{13-17}$ and POPs. ${ }^{7-9}$

\section{Conclusion}

Switching to the $\mathrm{E}_{2} \mathrm{~V} / \mathrm{DNG}$ pill resulted in a higher continuation rate and significantly increased continuation time than switching to a POP, with more women wanting to continue with the $\mathrm{E}_{2} \mathrm{~V} / \mathrm{DNG}$ pill than with the POP at the end of the observational study. This was confirmed by propensity score adjustment of treated patients to account for confounding variables, which showed significant differences between the two groups at baseline.

Generally, women who switched from an EE-containing $\mathrm{COC}$ to the $\mathrm{E}_{2} \mathrm{~V} / \mathrm{DNG}$ pill or to a POP had shorter, lighter, and more frequent absence of withdrawal bleeding. Additionally, in comparison to those receiving POP, women taking the $\mathrm{E}_{2} \mathrm{~V} / \mathrm{DNG}$ pill experienced less painful bleeding as well as less problematic (unscheduled) bleeding. Switching to the $\mathrm{E}_{2} \mathrm{~V} / \mathrm{DNG}$ pill was also associated with a higher degree of user satisfaction with around three-quarters of women expressing high satisfaction in addition to better physical and emotional well-being.

Both the $\mathrm{E}_{2} \mathrm{~V} / \mathrm{DNG}$ pill and POP were well tolerated, with low discontinuation rates due to AEs. The event pattern and the intensity of the TEAEs reported in this study were in line with the established safety profile of the $\mathrm{E}_{2} \mathrm{~V} / \mathrm{DNG}$ pill and POPs.

Overall, the CONTENT study shows that switching to the $\mathrm{E}_{2} \mathrm{~V} / \mathrm{DNG}$ pill can result in higher continuation rates and high user acceptability and satisfaction in the real-life setting when compared with a POP. The $\mathrm{E}_{2} \mathrm{~V} / \mathrm{DNG}$ pill may be an alternative option for women who are dissatisfied with their current pill.

\section{Acknowledgments}

Medical writing support was provided by Sudler \& Hennessey, Milan. Doctor Paula Briggs has received research support from Bayer Pharma AG, honoraria for participation in advisory boards from Bayer Pharma AG, Merck Sharp \& Dohme Limited, and Pfizer Limited; and sponsorship to attend meetings from Bayer Pharma AG, Merck Sharp \& Dohme Limited, and GlaxoSmithKline UK Limited. The study was funded by Bayer Pharma AG, Berlin, Germany.

\section{Disclosure}

Doctor Marco Serrani, Kai Vogtländer, and Doctor Susanne Parke are employees of Bayer Pharma AG. The authors report no other conflicts of interest in this work.

\section{References}

1. Christin-Maitre S. History of oral contraceptive drugs and their use worldwide. Best Pract Res Clin Endocrinol Metab. 2013;27(1): $3-12$.

2. Rosenberg MJ, Waugh MS. Oral contraceptive discontinuation: a prospective evaluation of frequency and reasons. Am J Obstet Gynecol. 1998;179(3 pt 1):577-582.

3. Rosenberg MJ, Waugh MS, Meehan TE. Use and misuse of oral contraceptives: risk indicators for poor pill taking and discontinuation. Contraception. 1995;51(5):283-288.

4. Moreau C, Bouyer J, Bajos N, Rodríguez G, Trussell J. Frequency of discontinuation of contraceptive use: results from a French populationbased cohort. Hum Reprod. 2009;24(6):1387-1392.

5. Kovacs G. Progestogen-only pills and bleeding disturbances. Hum Reprod. 1996;11(suppl 2):20-23.

6. Evans G, Sutton EL. Oral contraception. Med Clin North Am. 2015; 99(3):479-503.

7. Lawrie T, Helmerhorst F, Maitra N, Kulier R, Bloemenkamp K, Gülmezoglu AM. Types of progestogens in combined oral contraception: effectiveness and side-effects. Cochrane Database Syst Rev. 2011;5: CD004861.

8. Grimes DA, Lopes LM, O’Brien PA, Raymond EG. Progestin-only pills for contraception. Cochrane Database Syst Rev. 2013;11: CD007541.

9. Gallo MF, Nanda K, Grimes DA, Lopez LM, Schulz KF. $20 \mu \mathrm{g}$ versus $>20 \mu \mathrm{g}$ estrogen combined oral contraceptives for contraception. Cochrane Database Syst Rev. 2013;8:CD003989.

10. Palacios S, Wildt L, Parke S, Machlitt A, Römer T, Bitzer J. Efficacy and safety of a novel oral contraceptive based on oestradiol (oestradiol valerate/dienogest): a Phase III trial. Eur J Obstet Gynecol Reprod Biol. 2010;149(1):57-62.

11. Whalen KL, Rose R. Estradiol valerate/dienogest: a novel oral contraceptive. Ann Pharmacother. 2011;45(10):1256-1261.

12. Zeun S, Lu M, Uddin A, Zeiler B, Morrison D, Blode H. Pharmacokinetics of an oral contraceptive containing oestradiol valerate and dienogest. Eur J Contracept Reprod Health Care. 2009;14(3):221-232.

13. Jensen JT, Parke S, Mellinger U, Serrani M, Mabey RG Jr. Hormone withdrawal-associated symptoms: comparison of oestradiol valerate/ dienogest versus ethinylestradiol/norgestimate. Eur J Contracept Reprod Health Care. 2013;18(4):274-283. 
14. Macias G, Merki-Feld GS, Parke S, Mellinger U, Serrani M. Effects of a combined oral contraceptive containing oestradiol valerate/dienogest on hormone withdrawal-associated symptoms: results from the multicenter, randomised, double-blind, active-controlled HARMONY II study. J Obstet Gynaecol. 2013;33(6):591-596.

15. Petraglia F, Parke S, Serrani M, Mellinger U, Römer T. Estradiol valerate plus dienogest versus ethinylestradiol plus levonorgestrel for the treatment of primary dysmenorrhea. Int J Gynaecol Obstet. 2014; 125(3):270-274.

16. Fraser IS, Parke S, Mellinger U, Machlitt A, Serrani M, Jensen J. Effective treatment of heavy and/or prolonged menstrual bleeding without organic cause: pooled analysis of two multinational, randomised, double-blind, placebo-controlled trials of estradiol valerate and dienogest. Eur $J$ Contracept Reprod Health Care. 2011;16(4):258-269.
17. Davis S, Bitzer J, Giraldi A, et al. Change to either a nonandrogenic or androgenic progestin-containing oral contraceptive preparation is associated with improved sexual function in women with oral contraceptive-associated sexual dysfunction. J Sex Med. 2013;10(12): 3069-3079. 


\section{Supplementary materials \\ Propensity score methodology}

Propensity score methods (based on Austin ${ }^{1}$ ) were applied by an outcome-blinded third party (Stat-Epi Associates, Inc.) to account for allocation bias and possible confounding factors.

This method allowed for hypothetical randomization. Propensity score was estimated for each patient, using a logistic regression model, with treatment group indicator as the dependent variable and pretreatment baseline characteristics (including age, reason for discontinuation of EE-containing OCs, important medical history, such as thrombotic diseases, and bleeding pattern during preceding 3 months) as independent variables. The fitted values from the logistic regression yielded the estimated propensity scores, such that each score summarized an individual patient's pretreatment covariates. In order to balance covariates across the two treatment groups and allow unbiased estimation of the treatment effect, ten subclasses were created comprising patients who had similar estimated propensity score. These subclasses were then analyzed as if the study had been a stratified randomized experiment using a stratified Cox regression model.

\section{Study approval and reviewing boards}

Study approval was obtained by independent ethics committees or institutional review boards in each country where required (Table S1).

\section{Bleeding pattern at baseline}

Both study groups were well balanced in terms of the bleeding pattern at baseline, shown in Table S2.

\section{Emotional and physical well-being}

User-reported physical well-being and emotional well-being are depicted in Figure S1.

\section{Safety and tolerability}

Both the $\mathrm{E}_{2} \mathrm{~V} / \mathrm{DNG}$ pill and POP were generally well tolerated. The overall rates of all treatment-emergent adverse events (TEAEs) for $\mathrm{E}_{2} \mathrm{~V} / \mathrm{DNG}$ pill or POP are shown in Table S3.

Table SI Ethics committees and institutional review boards that approved the study

\begin{tabular}{|c|c|}
\hline Country & Reviewing board \\
\hline Czech Republic & - State Institute for Drug Control (SUKL) \\
\hline France & - Conseil Nacional de l'Ordre des Medicines \\
\hline Germany & $\begin{array}{l}\text { - Bundesinstitut für Arzneimittel und Medizinprodukte } \\
\text { - GKV: Spitzenverband } \\
\text { - KBV Kassenärztliche Bundesvereinigung }\end{array}$ \\
\hline Greece & $\begin{array}{l}\text { - National Drug Organization } \\
\text { - General Hospital of Thessaloniki “PAPAGEORGIOU”. Hospital Scientific Committee }\end{array}$ \\
\hline Hungary & - EGÉSZSÉGÜGYI TUDOMÁNYOS TANÁCS - Medical Research Council Scientific and Research Committee \\
\hline Israel & - EC: Maccabi Healthcare \\
\hline Italy & $\begin{array}{l}\text { - EC: Azienda Ospebaliera Universitaria Policlinio Paolo Giaccone die Palermo } \\
\text { - EC: Umberto I Policlinico die Roma } \\
\text { - EC: Azienda Ospedaliero Universitaria, Santa Maria de la Misericordia di Udine } \\
\text { - EC: Azienda Ospedaliero die Rilievo Nazionale e die alta Specializzazione "Garibaldi" } \\
\text { - EC: Universita di ferra, Servicio sanitario regionale Emilia Ramagna } \\
\text { - EC: Universitaria degli Studi die Napoli "Federicoll" } \\
\text { - EC: Azienda Ospedaliero, San Gerardo }\end{array}$ \\
\hline Russia & $\begin{array}{l}\text { - EC: Interuniversity ethic committee } \\
\text { - Ministry of Health }\end{array}$ \\
\hline Slovakia & $\begin{array}{l}\text { - SAFS: Slovenská asociácia farmaceutických spoločností orientovaných na výskum a vývoj } \\
\text { - State Institute for Drug Control SUKL } \\
\text { - EC: Ustredna Eticka komisia Bratislaveskeho samospravneho kraja }\end{array}$ \\
\hline Sweden & $\begin{array}{l}\text { - EC: Regionala etikprövningsnämnden i Uppsala } \\
\text { - Medical Product agency }\end{array}$ \\
\hline Great Britain & $\begin{array}{l}\text { - National Research Ethics Service } \\
\text { - Sussex NHS Research Consortium } \\
\text { - NHS Berkshire East } \\
\text { - NHS Leeds } \\
\text { - Liverpool NHS } \\
\text { - NHS: Comprehensive Local Research Network for Kent and Medway } \\
\text { - NHS York Hospitals }\end{array}$ \\
\hline
\end{tabular}


Table S2 Bleeding pattern during the preceding 3 months before enrollment (baseline visit, efficacy population)

\begin{tabular}{|c|c|c|c|c|c|c|}
\hline \multirow[t]{2}{*}{ Bleeding pattern parameters } & \multicolumn{2}{|c|}{ Total $(\mathbf{N}=3,150)$} & \multicolumn{2}{|c|}{$E_{2}$ V/DNG $(n=2,558)$} & \multicolumn{2}{|c|}{ POP $(n=592)$} \\
\hline & $\mathbf{n}$ & $\%$ & n & $\%$ & $\mathbf{n}$ & $\%$ \\
\hline \multicolumn{7}{|l|}{ Regularity of withdrawal bleeding } \\
\hline Regular (once a month) & 2,680 & 85.1 & 2,177 & 85.1 & 503 & 85.0 \\
\hline Occasionally absent & 426 & 13.5 & 351 & 13.7 & 75 & 12.7 \\
\hline Amenorrhea & 38 & 1.2 & 25 & 1.0 & 13 & 2.2 \\
\hline \multicolumn{7}{|l|}{ Maximum length of bleeding (days) } \\
\hline $1-2$ & 302 & 9.7 & 239 & 9.5 & 63 & 10.9 \\
\hline $3-5$ & 2,055 & 66.2 & 1,653 & 65.4 & 402 & 69.6 \\
\hline $6-7$ & 615 & 19.8 & 523 & 20.7 & 92 & 15.9 \\
\hline$\geq 8$ & 126 & 4.1 & 107 & 4.2 & 19 & 3.3 \\
\hline \multicolumn{7}{|l|}{ Maximum intensity of bleeding } \\
\hline Spotting & 205 & 6.6 & 164 & 6.5 & $4 \mathrm{I}$ & 7.1 \\
\hline Light/scanty & 681 & 21.9 & 541 & 21.4 & 140 & 24.2 \\
\hline Normal & $\mathrm{I}, 703$ & 54.8 & 1,397 & 55.3 & 306 & 52.9 \\
\hline Heavy & 500 & 16.1 & 411 & 16.3 & 89 & 15.4 \\
\hline \multicolumn{7}{|l|}{ Painful bleeding } \\
\hline Yes & 2,265 & 71.9 & $\mathrm{I}, 823$ & 71.3 & 442 & 74.7 \\
\hline No & 864 & 27.4 & 720 & 28.1 & 144 & 24.3 \\
\hline \multicolumn{7}{|c|}{ Intracyclic bleeding (more than once a month) } \\
\hline Yes & 2,676 & 85.0 & 2,157 & 84.3 & 519 & 87.7 \\
\hline No & 454 & 14.4 & 386 & 15.1 & 68 & 11.5 \\
\hline
\end{tabular}

Abbreviations: $E_{2} V / D N G$, estradiol valerate and dienogest; POP, progestogen-only pill.
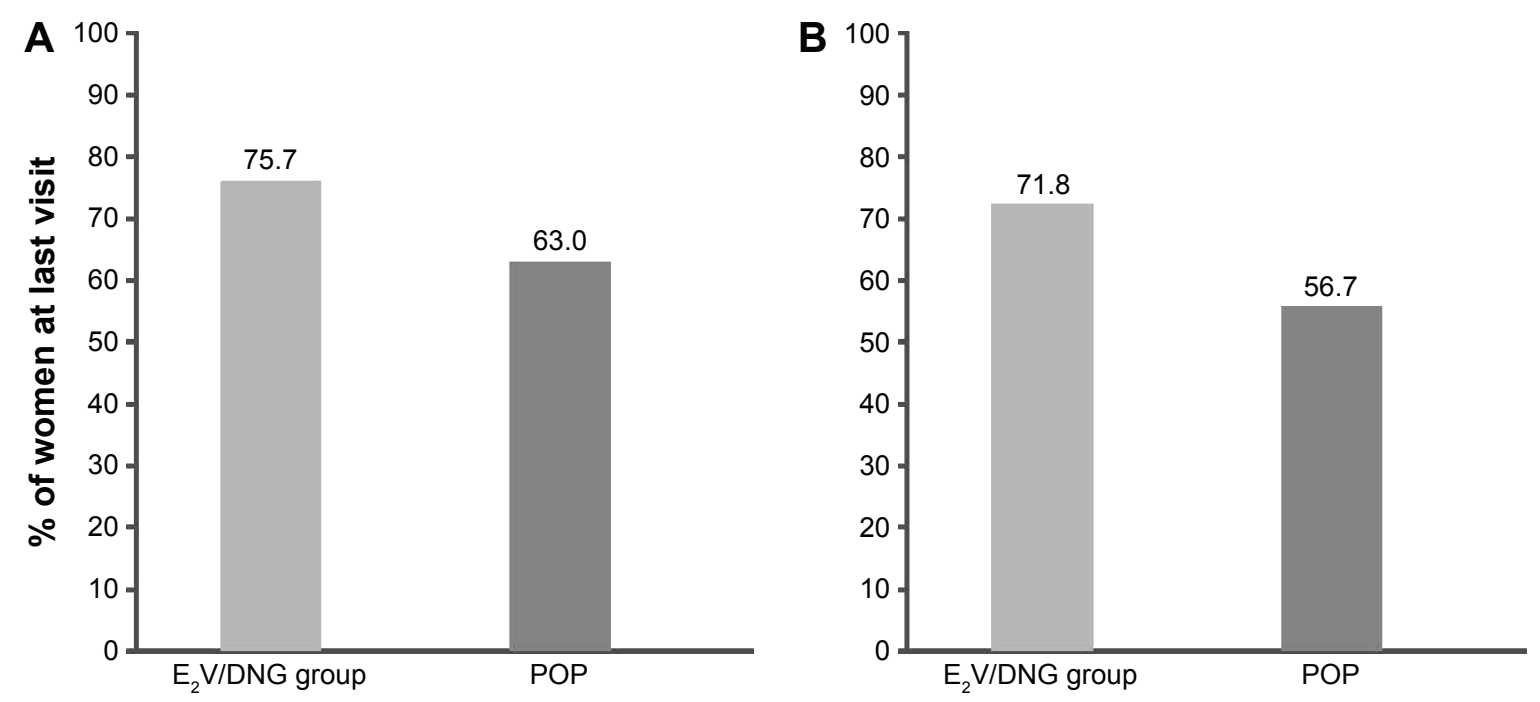

Figure SI Percentage of women who rated their $(\mathbf{A})$ physical or $(\mathbf{B})$ emotional well-being as "better" or "much better" at their last visit after switching to the $E_{2}$ V/DNG pill or POP.

Abbreviations: $E_{2} V / D N G$, estradiol valerate and dienogest; POP, progestogen-only pill. 
Table S3 Overview of TEAEs associated with $E_{2} V / D N G$ and POP use

\begin{tabular}{|c|c|c|c|c|c|c|}
\hline \multirow[t]{2}{*}{ Type of event } & \multicolumn{2}{|c|}{ Total $(\mathbf{N}=\mathbf{3}, 234)$} & \multicolumn{2}{|c|}{$E_{2}$ V/DNG $(n=2,629)$} & \multicolumn{2}{|c|}{ POP $(n=605)$} \\
\hline & $\mathbf{n}$ & $\%$ & $\bar{n}$ & $\%$ & $\mathbf{n}$ & $\%$ \\
\hline Overall adverse event rate & 262 & 8.1 & 194 & 7.4 & 68 & 11.2 \\
\hline Drug-related adverse events & 188 & 5.8 & 132 & 5.0 & 56 & 9.3 \\
\hline \multicolumn{7}{|l|}{ Serious adverse events } \\
\hline Nondrug related & 3 & 0.1 & 3 & 0.1 & 0 & 0.0 \\
\hline Drug related & 3 & 0.1 & 3 & 0.1 & 0 & 0.0 \\
\hline Deaths & 0 & 0.0 & 0 & 0.0 & 0 & 0.0 \\
\hline \multicolumn{7}{|l|}{ Discontinuation } \\
\hline Nondrug related & 179 & 5.5 & 132 & 5.0 & 47 & 7.8 \\
\hline Drug related & 145 & 4.5 & 102 & 3.9 & 43 & 7.1 \\
\hline
\end{tabular}

Abbreviations: $E_{2} V / D N G$, estradiol valerate and dienogest; POP, progestogen-only pill; TEAEs, treatment-emergent adverse events.

\section{Reference}

1. Austin PC. An Introduction to Propensity Score Methods for Reducing the Effects of Confounding in Observational Studies. Multivariate Behav Res. 2011;46(3):399-424.

\section{Publish your work in this journal}

The International Journal of Women's Health is an international, peerreviewed open-access journal publishing original research, reports, editorials, reviews and commentaries on all aspects of women's healthcare including gynecology, obstetrics, and breast cancer. The manuscript management system is completely online and includes a very quick and fair peer-review system, which is all easy to use. Visit http://www.dovepress.com/testimonials.php to read real quotes from published authors.

\footnotetext{
Submit your manuscript here: http://www.dovepress.com/international-journal-of-womens-health-journal
} 